\title{
Together all the bad things will disappear, I find my partner: Phenomenology study of online dating
}

\author{
Trisna Afdilla1,* \\ ${ }^{1}$ University of Muhammadiyah Malang, Indonesia \\ *Corresponding author: trisnaafdilla@gmail.com
}

\section{KEYWORDS}

Online dating

Motivation

Need affection and love

\begin{abstract}
The use of online dating applications has become a phenomenal social norm that is popular among the community of active social media users. Online dating activities are supported by the advancement of technology which resulted in abundance of affordable smartphones, hence everybody can easily find and meet locals as well as foreigners, which eventually might establish into a more serious relationship. This research aims to explore how an individual who is online dating addresses all the constraints and barriers the users experience and the motivation underlying the user in online dating to establish a relationship with the partner, which is certainly different from offline (classic) relationships. The research method used is a qualitative approach to the type of descriptive phenomenology. The number of subjects in this study were 8 people ( 3 men and 5 women), who had online dating relationship with someone from abroad. The results showed that some couples chose to learn to understand the culture and their limitations in establishing the relationship. Besides, some subjects chose to learn the language of their partner, and spending more time with their partner who had a regional time difference. The subjects had almost the same motivation in deciding to go for online dating. The fundamental thing that becomes a driver of an online dating relationship comes from the individual owns' desire to fulfill the needs of establishing a relationship with others to gain much needed attention, love, care and compassion.
\end{abstract}

(c) The Author(s) 2021

\section{INTRODUCTION}

The Internet provides many features that enable the users to connect with previously unknown virtual connections. The Internet became a widely used medium as a means of online interaction in social media (Abbasi, 2019). Technology can be used as a tool in communicating with other individuals by using various ways such as, sending messages, exchanging comments with each other, chatting publicly or direct private messages, and sending emails (Bagley \& Kimberly, 2017). One of the major achievements that came out of the development of internet is the birth of social media. Social Media is a place to go for many people in establishing relationships such as business and romantic relationships (Ouytsel, Gool, Walrave, Ponnet, \& Peeters, 2016). The experiment study conducted by (Weaver et al., 2018) listed its findings that the feeling of staying close to others becomes a determinant of the survival of community members in social networks.

Every human being has a need that is influenced by a personality that can be classified in fulfillment of selfachievement, the need for power, and compassion includes the need for life satisfaction (Saeednia \& Nor, 2013). The need for closeness and attachment to others as an attempt at social life to share the life story felt in every human being (Sparks, Schinkel, \& Moore, 2017). (Finkel, Eastwick, Karney,
Reis, \& Sprecher, 2012) states that with increasing age, the need to find life partner becomes more important. Several websites and dating apps (software) exists on social media that attract people to try them.

The introduction is aimed at achieving a similar goal of establishing a romantic online-based relationship. Freedom in choosing a partner provided by online dating sites make individuals able to fulfill their motives. The individuals involved in online dating have different motives. Someone building a relationship with another person is certainly not without a reason. Users of dating apps aim to gain affection, attract others' attention, and seek Romance (Wang, 2019). The effect of social and economic changes in establishing online relationships is considered to be a necessity in the fulfillment of life needs (Lee \& Hallak, 2020)

In the fulfillment process, the individual's warmth and affection must feel the comfort and attachment of communication. (Peltea, 2015) Such an attachment between the two people who are one of the things that need to be in the relationship. Attachment gives motivation and strength to maintain relationships. (Campbell, Nelson, Parker, L, \& Johnston, 2018)mentions that individuals need to be establishing close ties with other people online dating into a relationship as well as a fairly unique partner search process.

The purpose of this research is to explore the uniqueness of a friend's search that ended into marriage through 
online interaction process. Such as a phenomenology of the country's marriages that occur widely among people. This research aims to uncover individual motivations in establishing relationships with other individuals who come from different countries, and how online dating individuals overcome all the constraints and barriers that couples have, and also how the differences underlying online users in establishing relationships with their partners are generally different from offline classical relationships.

Online dating is basically a search for love or romance on the Internet through a dedicated website or software (Nam, 2017). Online romantic relationships are provided by many online dating service providers, and users of dating services can try to find a matching partner for themselves (Sari \& Kusuma, 2018). There is a wide variety of online dating sites on offer such as Twitter, Facebook, and Snapchat (Bagley \& Kimberly, 2017). Some users of online dating services feel there is a freedom to explore and show the profile of their lives. In addition, the ease of finding a suitable partner becomes easier. Online dating is a communication that is done without face-to-face by presenting yourself in an online application such as tinder and other apps (Sari \& Kusuma, 2018).

\section{METHOD}

This study used a qualitative approach with a phenomenological model for understanding the minds and the precarity of others. This research will describe how online dating users manage relationships that are intertwined with their partners with the barriers they face and the motivation of establishing relationships.

\subsection{Participants}

The Sample in this study amounted to 8 people who established an online dating relationship, 2 men with a bachelor's degree in education from USA, 1 man with postgraduate education background from Pakistan, and 5 women with a bachelor's degree in education. Sample ages of participants in this study were 25 years old to 31 years. Sample recruitment is done using the snowball sampling technique, this technique is recruiting samples by giving information to the friend of the sample who has a different country relationship.

\subsection{Data collection}

The collection of data is done by in-depth interview methods (in-depth interviews) through live interviews with faceto-face interviews via mobile phone and direct messaging via WhatsApp and Facebook. Participants are selected with interviews taken that correspond to the research criteria. Provision of criteria with participants who have relations with men or women with different nationalities.

\section{RESULT}

\subsection{The benefit of the internet}

It all started with the sophistication of Internet technology that eventually brings the couples together. Along with the need for a sense of warmth, being loved, familiarity, having others, all these makes some people encouraged to find their partners. The various ways of finding the ideal pair according to each other's wishes make people increasingly motivated to find a loving partner, the many ways each person takes varies depending on the individual itself. Some people choose to make social media a place where they find couples for a variety of reasons until they proceed to the stage of selecting meeting face-to-face. A beginning that starts from the Internet continues to be an exciting journey, as disclosed by one of the research subjects :

"Initially because I had a new Mobile, I immediately downloaded the application Line, and in the application line there was an advertisement post, so I downloaded the application that appears on the advertisement and the app live chat, then he did a live broadcast and I gave love, after which he sent me a message, until intertwined communication every day"

The subject felt that after she had a new mobile Android-based made the subject find new things and a new world, had new friends he knew over the internet and eventually headed on fairly active and close communication, which made the subject interested in establishing a relationship dating with someone new he knew from the Internet. Various dating apps offered in cyberspace made the subject feel easy in finding new friends, discovering new characters that have never been subject to meet in their country, the sophistication of the Internet provides a new part in making it easy for users to access all the wishes of users who lead to unintentional encounters that become a new alternative that is pleasant enough for some communities in the discovery of a live partner.

\subsection{Motivation}

In finding a life partner everyone has different motives in establishing relationships with others. As the age grows the need for compassion is getting higher that encourages someone to find a friend as a social form. In the study it is known that the subject has different reasons for choosing his partner. As on any of the subjects that have a spouse from America says:

"Other than I feel appreciated, and in love, I feel that he is very good to me, my life is financed by the man, he always gives me dollar with quite a lot of amount every week, I can buy anything I want and do whatever I want, he freed me friends with many men, I feel that there is no rule that makes me a man like this I do not find in my country"

The subject feels that when the subject is with a male originating from another country, the subject obtains considerable attention and feels unwrapped without a rule unlike by the subject, as well as the subject feels to get what the subject wants, with the couple giving it money and freedom, the subject feels unable to resist and is motivated to continue to establish a relationship with a different countryman compared to the man who came from his country is not like a man from another country.

\subsection{Difference between different country pairs}

In addition to having different motives in establishing relationships with men or women originating from different countries, the subject also feels a lot of difference between men from their own country, and women from their own countries have a distinctive difference in their love affair. As the 2 subjects expressed in this study:

"Yes it is very different, men from other countries very romantic, attention, every day say (I love you), every day 
told me if I am beautiful, however man who came from my country are not romantic but arrogant instead"

The other sample subject said :

"The difference is very clear yes, I live for 28 years, but never have a boyfriend, I was introduced by my friend to his friend from another country, I probably do not have a beauty standard in the eyes of my country, the man in my country has a very high standard of beauty, I do not match in my country, because I am ugly, but after familiar with men from other, she said I was beautiful, very pretty, and she always said (I love you) every day"

The two statements expressed by the subjects it is obvious that the subjects feel more appreciated, at the same, more on the look and beauty. The subject feels that when establishing a relationship with a spouse that does not belong to the country is more romantic. The difference is enough to make the subject feel comfortable with their relationship despite the considerable distance between his country and his partner country.

\subsection{Communication Barriers}

The various obstacles faced by couples who establish online dating relationship must be much heavier than the relationship done offline or locally. The main thing that becomes an obstacle in establishing an online dating relationship is the language. Language becomes a big obstacle when one has to communicate with the partner. The different pronunciation and limitation of vocabulary in forming a conversation is an obstacle for them. But despite the many obstacles they face, they still persist to establish communication with their partners.

"Our relationship constraint is language barrier because he cannot speak my language, moreover, his English is weak too and I can not speak Bahasa Indonesia, but I love him. I taught him English"

The limitations of the language differences that are being faced by the subjects became an obstacle in the communication of both parties, but not only the language that became an obstacle, some subjects reported that time difference also became a barrier other than the language, as quoted from one of America's subjects said that:

"It's hard for me to communicate with my lady and have to spend lesser time, because of the time difference, for example when its $10 \mathrm{am}$. in my country, its already midnight at my woman's home, that's why sometimes we quarrel".

\subsection{Together all difficulties will disappear}

With the abundance of language barriers and different timezones problems, the subjects are convinced that if they are together they will be able to pass through all the obstacles and get over all the bad things that may happen. Based on the experience of some subjects explaining that they are confident they will be able to pass through obstacles if they stay together. As one of the research subjects stated:

"I quite understand the obstacles in our relationship is language barrier, I try to learn my partner's language, I teach my language, sometimes we share and laugh in my language, we believe that we can conquer this challenge when we are sharing".

When realizing that there is a difference in language perceived by the subjects to be a big thing that is quite challenging and becomes problematic, the subjects sought to solve barriers in language differences by learning the lan- guage of their partners, and practicing the dialogues with their partners. Although language differences were challenging, with the sense of love and compassion for their partners and with the hard work together, subjects were able to shrink the gap of language barrier that they had.

\section{DISCUSSION}

With the internet all relationships can be built in the community of business, politics, and also Romance (Weaver et al., 2018). It can be said that Internet development has a considerable impact on community interpersonal relationships. From a wide range of social interaction media offering different things in the search for friends, users can determine which partner matches them by sharing information and profiles.

With the Internet that has created a new space for people to be able to find their partner. This is based on decision making that is sequentially facilitated by the Internet, the individual can determine the prospective partner that he wants and allows greater opportunity to find the partner according to individual desires (Whyte \& Torgler, 2017) The introduction done aims to achieve a similar goal in establishing an online-based romantic relationship. Some subjects explained that with the presence of the internet and social media, the subject was finally able to get a partner. (Berlin, 2014) Most users of online dating services in America accept that online dating is the best way to find a better partner.

The user of social media such as line, whatsApp, instagram, bado that allows a person to meet his partner is a thing that is already very popular among the public, so many people are interested in using it for various reasons (Xin et al., 2018). In establishing a relationship a subject says that the subject prefers to men of different countries because it is considered not to have many rules. (Gavin, Rees-Evans, Duckett, \& Brosnan, 2019). In online dating relationships, some people offer a decrease in the demands of others when they are in a relationship.

The subjects felt gaining more attention, feeling in love, feeling able to be yourself, feeling able to carrying out the conversations and bringing out the thoughts freely, get affection, get entertained, and get financially supported. (Young, Len-Ríos, \& Young, 2017) study states that most of the motivation from Internet use is establishing a close relationship, as well as being entertained. The subjects say that when they experienced an online dating relationship, they feel more understandable and get the relationship they want as the relationship is open and full of love. This becomes an advantage that the subject has gained. This is an advantage that the subjects get. Although sometimes there is a lack of trust (Evans, Stavrova, \& Rosenbusch, 2021). In other studies mention that love is a psychological factor as motivation to establish close relationships with others (Burunat, 2019).

\section{SUMMARY}

Establishing relationships with others, gaining affection, love, and emotional and financial support has become a psychological fulfillment of needs for every individual. And, various internet developments and social media development presenting online dating services have made it easy for someone to find a partner that is considered suitable and capable of being a partner. Several online site sites are 
often found in the form of Twitter, Bado, Facebook, Online dating website, is an online dating service provider that can also be tried. The findings of this research have explored the motivation of a person who often establishes relationship with online strangers and especially foreigners, by not making obstacles as a disconnect but as a struggle to be done together. The result of this study mentions that almost all subject said that the sense of love, compassion, attention, and financial support becomes a motivation in establishing a different country relationship. The subjects felt that couples coming from the same country did not behave in same way as others.

\section{REFERENCES}

Abbasi, I. S. (2019). Social media addiction in romantic relationships: Does user's age influence vulnerability to social media infidelity? Personality and Individual Differences, 139(October 2018), 277-280. https://doi.org/10.1016/j.paid.2018.10.038

Bagley, L. A., \& Kimberly, C. (2017). Technology use and its association with romantic relationships. Contemporary Perspectives in Family Research, 11, 217-236. https://doi.org/10.1108/S1530-353520170000011010

Berlin, R. (2014). The professional ethics of online dating: Need for guidance. Journal of the American Academy of Child and Adolescent Psychiatry, 53(9), 935-937. https://doi.org/10.1016/j.jaac.2014.05.017

Burunat, E. (2019). Love is a physiological motivation (like hunger, thirst, sleep or sex). Medical Hypotheses, 129(December 2018), 109225. https://doi.org/10.1016/j.mehy.2019.05.011

Campbell, K., Nelson, J., Parker, L, M., \& Johnston, S. (2018). Interpersonal chemistry in friendships and romantic relationships. Interpersona, 12(1), 34-50. https://doi.org/10.5964/ijpr.v12i1.289

Evans, A. M., Stavrova, O., \& Rosenbusch, H. (2021). Expressions of doubt and trust in online user reviews. Computers in Human Behavior, 114(January 2020), 106556. https://doi.org/10.1016/j.chb.2020.106556

Finkel, E. J., Eastwick, P. W., Karney, B. R., Reis, H. T., \& Sprecher, S. (2012). Online Dating: A Critical Analysis From the Perspective of Psychological Science. Psychological Science in the Public Interest, Supplement (Vol. 13). https://doi.org/10.1177/1529100612436522

Gavin, J., Rees-Evans, D., Duckett, A., \& Brosnan, M. (2019). The attractiveness, trustworthiness and desirability of autistic males' online dating profiles. Computers in Human Behavior, 98(April), 189-195. https://doi.org/10.1016/j.chb.2019.04.016

Lee, C., \& Hallak, R. (2020). Investigating the effects of offline and online social capital on tourism SME performance: A mixed-methods study of New Zealand entrepreneurs. Tourism Management, 80(February), 104128. https://doi.org/10.1016/j.tourman.2020.104128

Nam, T. (2017). Who is dating and gaming online? Categorizing, profiling, and predicting online daters and gamers. Computers in Human Behavior, 73, 152-160. https://doi.org/10.1016/j.chb.2017.03.044

Ouytsel, J. Van, Gool, E. Van, Walrave, M., Ponnet, K., \& Peeters, E. (2016). Computers in Human Behavior Exploring the role of social networking sites within adolescent romantic relationships and dating experi- ences. Computers in Human Behavior, 55, 76-86. https://doi.org/10.1016/j.chb.2015.08.042

Peltea, B. B. (2015). Couple Construction and Couple Relationship in Various Western Femininity Paradigms. Procedia - Social and Behavioral Sciences, 187, 390-395. https://doi.org/10.1016/j.sbspro.2015.03.073

Saeednia, Y., \& Nor, M. M. D. (2013). Measuring Hierarchy of Basic Needs among Adults. Procedia - Social and Behavioral Sciences, 82, 417-420. https://doi.org/10.1016/j.sbspro.2013.06.285

Sari, W. P., \& Kusuma, R. S. (2018). Presentasi Diri dalam Kencan Online pada Situs dan Aplikasi Setipe dan Tinder. Mediator: Jurnal Komunikasi, 11(2), 155-164. https://doi.org/10.29313/mediator.v11i2.3829

Sparks, E., Schinkel, M. G., \& Moore, C. (2017). Affiliation affects generosity in young children: The roles of minimal group membership and shared interests. Journal of Experimental Child Psychology, 159, 242-262. https://doi.org/10.1016/j.jecp.2017.02.007

Wang, Y. S. (2019). Virtual cohabitation in online dating sites: a netnography analysis. Online Information Review, 43(4), 513-530. https://doi.org/10.1108/OIR-112016-0338

Weaver, I. S., Williams, H., Cioroianu, I., Williams, M., Coan, T., \& Banducci, S. (2018). Dynamic social media affiliations among UK politicians. Social Networks, 54, 132144. https://doi.org/10.1016/j.socnet.2018.01.008

Whyte, S., \& Torgler, B. (2017). Things change with age: Educational assortment in online dating. Personality and Individual Differences, 109, 5-11. https://doi.org/10.1016/j.paid.2016.12.031

Xin, M., Xing, J., Pengfei, W., Houru, L., Mengcheng, W., \& Hong, Z. (2018). Online activities, prevalence of Internet addiction and risk factors related to family and school among adolescents in China. Addictive Behaviors Reports, 7, 14-18. https://doi.org/10.1016/j.abrep.2017.10.003

Young, R., Len-Ríos, M., \& Young, H. (2017). Romantic motivations for social media use, social comparison, and online aggression among adolescents. Computers in Human Behavior, 75, 385-395. https://doi.org/10.1016/j.chb.2017.04.021 